\title{
TIN-DS/AHP: An Intelligent Method for Group Multiple Attribute Decision Making
}

\author{
Yuanwei Du*, Chen Han, Youguo Jing and Jing Liu \\ Faculty of Management and Economics, Kunming University of Science and Technology, 650093 Kunming, China
}

Received: 20 Apr. 2013, Revised: 21 Aug. 2013, Accepted: 23 Aug. 2013

Published online: 1 Mar. 2014

\begin{abstract}
The group decision-making problems with several experts and seriously different opinions are unable to be solved by current existing DS/AHP methods. In order to solve above problems, a derived model is constructed to recognize the optimal Basic Probability Assignment (BPA) functions from TIN knowledge matrices by introducing deviation variables. After that, a modified model and its corresponding modified theorems for improving TIN knowledge matrices are proposed to overcome matrix inconsistencies and provide expert group for defining discussed problem as well as guiding improvement direction. The intelligent decision making procedure is presented in terms of intelligent human-machine interaction and decision, and a comparative analysis with numerical values shows the proposed method is scientific, reasonable, and well applicable finally.
\end{abstract}

Keywords: DS/AHP, three-point internal number, intelligent decision method, multiple attribute decision making, group decision making

\section{Introduction}

The DS/AHP is a hybrid multiple criteria decision making method by combining Analytic Hierarchy Process (AHP) and Dempster-Shafer Theory(DST), which is introduced by Beynon in 2000 to comprehensively integrate judgment deduced by experts. [1]. It used the hierarchical structure of AHP to making the whole decision process more approximate to human intuition thinking mode for evaluating priority values. While from DST, it imported group scheme method to extract subjective decision information that can use less information to pick up high quality results. The combination of DST in DS/AHP acknowledged the concomitant ignorance in the decision-making process. This ignorance here might be from lacking of knowledge on certain alternative, the inability of distinguishing preference levels among alternatives or alternative groups, even the bounded rationality problem [2]. In fact, ignorance above suggests that the decision result by using traditional decision method might be unspecific when the number of alternatives is large. For solving this problem, Beynon had put forward several literatures latter.

The original DS/AHP introduced by Beynon in 2000 was brief for that paper mainly exposited the DST as a multiple criterion decision making method [1,3]. Developments of DS/AHP were undertaken and the formal DS/AHP was put forward in 2002, of which Beynon acknowledged a lack of mathematical stringency in original DS/AHP. What's more, explicit mathematical analysis was constructed for the Basic Probability Assignments (BPA) function representing levels of preference to alternative groups given in a knowledge matrix for a specific criterion [4]. Eversince, DS/AHP method had been established officially, in this paper, it's called nascent DS/AHP. For making group decision, an aggregation method of DS/AHP developed by Beynon in 2005, in which described a group decision-making method by using definition of importance weight of experts for their non-equivalent importance [5]. Proved by a numerical problem, DS/AHP could solve ordinary group decision-making issue as well.

As an efficient decision-making method, DS/AHP has already been used in power system planning, strategic opportunities optimization, organization personnel selection, human capital optimization, and etc $[6,7,8,9]$. Except Beynon, since the existence of ignorance above, improving researches based on fuzzy information were proceeded. In distance, by constructing incomplete decision matrix to distinguish possible focal elements,

\footnotetext{
* Corresponding author e-mail: duyuanwei@gmail.com
} 
and combining DST, Hua put forward a method named 'DS-AHP' [10]. By using interval comparison matrix and interval reliability structure, Yue has studied an improving DS/AHP method [11]. Aimed at multilayer decision problem with incomplete and imprecise decision information, Utkin has expanded DS/AHP method based on linear programing model [12]. Particular attention is, researches above are expanded applications by acknowledging rationality of DS/AHP, or method improving under condition of slack information accuracy. Two kinds of researches belong to field of individual decision since their implication of there being one expert, or viewpoint of all the experts is completely consistent. Thus, for more general group decision-making within reality existing a number of experts or seriously different experts' opinions, they are always lose efficiency.

Although the group DS/AHP method introduced by Beynon can integrate a number of experts' opinions [5], it just considered the non-equivalent importance of group members, what hasn't been described the possibility of decision result disabled due to huge conflicts caused by different knowledge background and subjective diversities of opinions. Let alone the dynamic revise to decision information for deepening experts' understanding by using interactive discussion. Fortunately, Three-point Interval Number (TIN) is presented as a novel approach to measure experts' judgment information on the premise of complexity of decision problem and fuzziness of human thought [13]. Comparing with traditional uncertain methods as fuzzy number and interval number, using the TIN method to describe decision information on one hand could overcome the defect of information losing during the assembly process, on the other hand could prevent disabled decision results caused in disperse experts' opinions $[14,15]$.

On that account, this paper will fuse TIN method and nascent DS/AHP. In the rest part, definitions as 'TIN knowledge matrix', BPA function and its determining model will be described. By using these definitions, the deducing information of experts could be described, the modified model and theorem of TIN knowledge matrix could be built, and then an intelligent method named TIN-DS/AHP will be proposed to solve multiple attribute group decision making problems. The structure of the rest of the paper is as follow: Section 2 briefly describes the relevant theories of DS/AHP and TIN by using a series of definitions, including the basic principles of both. Section 3 develops BPA function determining model by introducing TIN knowledge matrix. Section 4 modifies the TIN knowledge matrix to strengthen the scientificalness of knowledge matrix deduced by experts. Section 5 discusses intelligent decision making process of TIN-DS/AHP, including exposition in details. Section 6 gives a numerical comparative analysis to prove the scientific validity and practical feasibility of TIN-DS/AHP. Section 7 is a conclusion of this whole paper.

\section{Relevant Theories}

The fundamental of nascent DS/AHP is as follows. First of all, dividing all the alternatives into alternative groups within different importance levels and constructing knowledge matrices in specific attributes by making a relatively importance judgment through comparing every alternative group with the Frame of Discernment (consist of all of alternatives). After that, solving the eigenvector of the largest eigenvalue of knowledge matrices to obtain the BPA functions, and using Dempster rule to fuse all of BPA functions by treating each attribute as an independent evidence source. Finally, utilizing Belief function or Plausibility function to rank alternatives [4].

Definition 1 Suppose a possible hypothesis of variable is $\theta_{i}(i=1, \cdots, I)$, each of possible hypotheses is exclusive, then a finite nonempty exhaustive set of all possible hypotheses $\Theta=\left\{\theta_{i} \mid i=1, \cdots, I\right\}$ is called Frame of Discernment. In this paper, the Frame of Discernment means a gather made of all the alternatives.

Definition 2 Let $2^{\Theta}$ as gather of all the subsets of Frame of Discernment $\Theta$, the nonvoid subset and reliability of $\Theta$ are $A$ and $m(A)$, if the mapping function $m: 2^{\Theta} \rightarrow[0,1]$ could fulfill

$$
m(\varnothing)=0, \sum_{A \subseteq \Theta} m(A)=1,
$$

then $m(\cdot)$ is called BPA function of $\Theta$. If $m(A)>0$, named $A$ as focal element.

Definition 3 Suppose $m_{j}$ is the BPA function of evidence source $E_{j}$, focal element is $A_{j}^{(n)}, n=1, \cdots, N_{j}, j=1, \cdots$, $J, K=\sum_{\cap_{j} A_{j}^{(n)}=\varnothing}\left[\prod_{j} m_{j}\left(A_{j}^{(n)}\right)\right]$, then Dempster combining rule for all of BPA functions could be expressed as

$$
m(\varnothing)=0, m(A)=\frac{1}{1-K} \sum_{\cap_{j} A_{j}^{(n)}=A}\left[\prod_{j} m_{j}\left(A_{j}^{(n)}\right)\right] .
$$

Definition 4 Suppose $A_{j}^{(n)}\left(n=1, \cdots, N_{j}\right)$ is a possible proposition or proposition set concluded by experts on the $j$-th attribute, $v_{j}^{(n)}$ is a relative importance value that $A_{j}^{(n)}$ to $\Theta$ deduced by experts with 2-6 scale, $A_{j}^{(n)} \cap A_{j}^{\left(n^{\prime}\right)}=\varnothing$, $v_{j}^{(n)} \neq v_{j}^{\left(n^{\prime}\right)}, n \neq n^{\prime}, n=1, \cdots, N_{j}$, then

$$
V_{j}=\left[\begin{array}{ccccc}
1 & 0 & \cdots & 0 & v_{j}^{(1)} \\
0 & 1 & \cdots & 0 & v_{j}^{(2)} \\
\vdots & \vdots & \ddots & \vdots & \vdots \\
0 & 0 & \cdots & 1 & v_{j}^{\left(N_{j}\right)} \\
1 / v_{j}^{(1)} & 1 / v_{j}^{(2)} & \cdots & 1 / v_{j}^{\left(N_{j}\right)} & 1
\end{array}\right]
$$

is the experts' knowledge matrix in the $j$-th attribute. 
Note that, the "2-6 scale" means if experts thought $A_{j}^{(n)}$ is 'extremely preferred' and 'general preferred' than $\Theta$, then the relative importance value should be assigned by 6 and 2, else if it is between 'extremely preferred' and 'general preferred', then the relative importance value should be assigned by a integer value between 6 and 2 . The normalized eigenvector corresponding to the largest eigenvalue of knowledge matrix $V_{j}$ is the BPA function of proposition or proposition set $A_{j}^{(n)}\left(n=1, \cdots, N_{j}\right)$ and ignorance $\Theta$ [16].

The Belief function and the Plausibility function respectively denote the minimum and the maximum belief level of proposition or proposition set [17], thus it is unilateral to select one of them to make decision, whereas more reasonable method is comprehensively considering decision contributions of both of them to making decision. For example, when the Belief functions of alternatives are all the same, the magnitudes of Plausibility functions could decide the merits. On contrast, when they have same Plausibility functions, the determinant should be the Belief function. To guarantee the criterion rationality designed for ranking alternatives, we introduce the Pignistic probability to be the evaluation criterion which could effectively integrate Belief function and Plausibility function.

Definition 5 Suppose the Belief function and the Plausibility function of proposition $\theta_{i}$ are respectively $\operatorname{Bel}\left(\theta_{i}\right)=\sum_{B \subseteq \theta_{i}} m(B)$ and $\operatorname{Pl}\left(\theta_{i}\right)=\sum_{\theta_{i} \cap B \neq \varnothing} m(B)$, let $\varepsilon=\left[1-\sum_{\theta_{i} \subseteq \Theta} \operatorname{Bel}\left(\theta_{i}\right)\right] / \sum_{\theta_{i} \subseteq \Theta} P l\left(\theta_{i}\right)$, then the Pignistic probability of $\theta_{i}$ is

$$
P\left(\theta_{i}\right)=\operatorname{Bel}\left(\theta_{i}\right)+\varepsilon \cdot P l\left(\theta_{i}\right), \quad i=1, \cdots, I .
$$

During the process extracting decision information, it not only needs to consider the differences of knowledge structure of experts' group, but also needs to reasonably balance the dispersing degrees. The reasons lies in: first of all, the differences of research areas, professional backgrounds and other aspects could induce opinion of each expert to be independent, and these opinions might be expressed by different forms. For instance, some would express their opinions by a ratio of alternatives to Frame of Discernment, but others would express them by a ratio between two alternatives. Secondly, it is impractical to require all of the experts to give completely consistent information and it is unallowed that their deduced information to be too dispersed. Because the former means there might be existing group thinking phenomenon [18], and the latter means experts' acquaintances of decision issue are not profound enough as well as the information need to be discussed deeply. For above purpose, knowledge matrix in (3) could not rationally and roundly describe the information deduced by expert group. Therefore, based on expanding construction manner of traditional matrix, this paper imports TIN into knowledge matrix as information carrier of extracting deduce values of experts' group.
TIN was a array with minimum, most likely value (also known as gravity center) and maximum, to represent experts' reasoning judgments for special decision issues depending on subjective knowledge experiences. During the process of judgment, experts deliberate surrounding the decision issue, if distribution probability of some deducing value reaches a particular threshold $\delta$ ( $\delta$ usually equal to $60 \%$ ), then we define this value as the most likely value, else it reflects experts' opinions are too dispersive and needs to be reviewed and deliberated again. After discussion, the most optimistic value and the most pessimistic value given by experts are treated as the maximum and the minimum of TIN to reflect fluctuation range of all the experts' opinions. We will use TIN to describe experts' group judgment information of knowledge matrix and solve BPA function depending on this information in the later. Thus following definition is given specially.

Definition 6 Suppose $A_{j}^{(n)}$ is a proposition or proposition set with specific importance level in the $j$-th attribute, $\tilde{v}_{j}^{\left(n n^{\prime}\right)}=\left[\overleftarrow{v}_{j}^{\left(n n^{\prime}\right)}, \bar{v}_{j}^{\left(n n^{\prime}\right)}, \mathbf{v}_{j}^{\left(n n^{\prime}\right)}\right]$ is the relative importance level that $A_{j}^{(n)}$ to $A_{j}^{\left(n^{\prime}\right)}\left(n \neq n^{\prime}\right)$ or $\Theta$, which is given by experts' group after interactive discussion within TIN and "1-9 scale", and the distribution probability of $\bar{v}_{j}^{(n)}$ could fulfill the demanding of particular threshold $\delta$, then

$$
\tilde{V}_{j}=\left[\begin{array}{ccccc}
1 & \tilde{v}_{j}^{(12)} & \cdots & \tilde{v}_{j}^{\left(1 N_{j}\right)} & \tilde{v}_{j}^{\left(1\left(N_{j}+1\right)\right)} \\
\tilde{v}_{j}^{(21)} & 1 & \cdots & \tilde{v}_{j}^{\left(2 N_{j}\right)} & \tilde{v}_{j}^{\left(2\left(N_{j}+1\right)\right)} \\
\vdots & \vdots & \ddots & \vdots & \vdots \\
\tilde{v}_{j}^{\left(N_{j} 1\right)} & \tilde{v}_{j}^{\left(N_{j} 2\right)} & \cdots & 1 & \tilde{v}_{j}^{\left(N_{j}\left(N_{j}+1\right)\right)} \\
\tilde{v}_{j}^{\left(\left(N_{j}+1\right) 1\right)} & \tilde{v}_{j}^{\left(\left(N_{j}+1\right) 2\right)} & \cdots & \tilde{v}_{j}^{\left(\left(N_{j}+1\right) N_{j}\right)} & 1
\end{array}\right]
$$

is TIN knowledge matrix in the $j$-th attribute given by experts' group.

Need to be noted are: firstly, 1-9 scale means if an expert thought comparing with another element, one element is equally important, slightly important, obviously important, quietly important or extremely important, the values are 1, 3, 5, 7, 9. On contrast, the values are $1,1 / 3,1 / 5,1 / 7,1 / 9$. Of course, these values could also assign between these given values above depend on their importance level. Using 1-9 scale is for giving larger scale range to experts, by which can raise accuracy of information. Secondly, TIN knowledge matrix permits the existing of incomplete element, namely when experts' group considers needn't or couldn't make deduction to a proposition set $A_{j}^{(n)}$ relative to $A_{j}^{\left(n^{\prime}\right)}\left(n \neq n^{\prime}\right)$ or preference degree question of $\Theta$, they can assign empty value to corresponding element in matrix. Nevertheless, except diagonal elements, TIN knowledge matrix $\tilde{V}_{j}$ has to have more than one 
non-empty element each row and column, to guarantee at least once reasoning judgment to every alternative group.

Definition 7 Suppose $m_{j}^{(n)}\left(n=1, \cdots, N_{j}+1\right)$ is the BPA function of proposition or proposition set $A_{j}^{(n)}$ and Frame of Discernment $\Theta$ in $j$-th attribute with respect to decision issue $Q$. If non-empty element of TIN knowledge matrix $\tilde{V}_{j}$ and BPA function vector quantity $\left(m_{j}^{(n)} \mid n=1, \cdots, N_{j}+1\right)$ could fulfill

$$
\left\{\begin{array}{l}
\bar{v}_{j}^{\left(n n^{\prime}\right)}=m_{j}^{(n)} / m_{j}^{\left(n^{\prime}\right)}, \bar{v}_{j}^{\left(n n^{\prime}\right)} \neq \varnothing \\
\overleftarrow{v}_{j}^{\left(n n^{\prime}\right)} \leq m_{j}^{(n)} / m_{j}^{\left(n^{\prime}\right)} \leq \mathbf{v}_{j}^{\left(n n^{\prime}\right)}, \overleftarrow{v}_{j}^{\left(n n^{\prime}\right)} \neq \varnothing, \mathbf{v}_{j}^{\left(n n^{\prime}\right)} \neq \varnothing
\end{array}\right.
$$

then TIN knowledge matrix $\tilde{V}_{j}$ has complete consistency.

\section{Determining BPA function model}

Suppose that experts' group wants to rank $I$ alternatives by using $J$ attributes, where alternative set is $\left\{a_{i} \mid i=1, \cdots, I\right\}$, and attribute set is $\left\{c_{j} \mid j=1, \cdots, J\right\}$, so, TIN knowledge matrix given by experts' group in attribute $c_{j}$ is $\tilde{V}_{j}, j=1, \cdots, J$. For traditional knowledge matrix, normalized eigenvector corresponding to largest eigenvalue is treated as BPA function of every alternative group according to DS/AHP method. The essence of this thought is trying to recognize one BPA function which is satisfying all pairwise comparison constraints furthest from knowledge matrix. What's more, for TIN knowledge matrix, the elements not only include gravity center which can reflect most experts' deducing opinions, but also include maximum and minimum values which can reflect most optimistic and most pessimistic opinions. Thus the BPA functions corresponding to TIN knowledge matrix not only fulfill pairwise comparison constrain (expressed as gravity center) mentioned in traditional knowledge matrix, but also restricted in the fluctuation range of experts' deducing opinions (expressed as maximum and minimum values). The complexity of decision context and the finiteness of subjective cognition ability bring about a problem that TIN knowledge matrix given by subjective inference could not reach complete consistency in general condition. That is, instead of ideal BPA function (see (6)), the optimal BPA function which could fulfill all the constraint conditions with minimum deviation definitely exists. Following above ideas,by introducing deviation variable, this paper will construct a determining model that could recognize optimal BPA functions from TIN knowledge matrix by introducing deviation variable.

Let BPA function variables in attribute $c_{j}$ corresponding to alternative group $A_{j}^{(n)}$ and Frame of Discernment $\Theta$ is $m_{j}^{(n)}\left(n=1, \cdots, N_{j}\right)$ and $m_{j}^{\left(N_{j}+1\right)}$, respectively. Then the relationship between $m_{j}^{(n)} / m_{j}^{\left(n^{\prime}\right)}$ and $\tilde{v}_{j}^{\left(n n^{\prime}\right)}=\left[\overleftarrow{v}_{j}^{\left(n n^{\prime}\right)}, \bar{v}_{j}^{\left(n n^{\prime}\right)}, \mathbf{v}_{j}^{\left(n n^{\prime}\right)}\right]$ could be represented by
Fig. 1. As shown in Fig. 1, there might be varying levels deviation between $m_{j}^{(n)} / m_{j}^{\left(n^{\prime}\right)}$ and TIN deducing value $\tilde{v}_{j}^{\left(n n^{\prime}\right)}=\left[\overleftarrow{v}_{j}^{\left(n n^{\prime}\right)}, \bar{v}_{j}^{\left(n n^{\prime}\right)}, \mathbf{v}_{j}^{\left(n n^{\prime}\right)}\right]$. Let the deviation generated by $\bar{v}_{j}^{\left(n n^{\prime}\right)}$ as $d_{j}^{\left(n n^{\prime}\right)}$ or $e_{j}^{\left(n n^{\prime}\right)}$, the deviations generated by $\overleftarrow{v}_{j}^{\left(n n^{\prime}\right)}$ and $\mathbf{v}_{j}^{\left(n n^{\prime}\right)}$ as $f_{j}^{\left(n n^{\prime}\right)}$ and $g_{j}^{\left(n n^{\prime}\right)}$. Obviously, when $m_{j}^{(n)} / m_{j}^{\left(n^{\prime}\right)}$ is separately located in the area 1 to 4 , the total deviations generated by $\tilde{v}_{j}^{\left(n n^{\prime}\right)}$ are $f_{j}^{\left(n n^{\prime}\right)}+d_{j}^{\left(n n^{\prime}\right)}, d_{j}^{\left(n n^{\prime}\right)}$, $e_{j}^{\left(n n^{\prime}\right)}, e_{j}^{\left(n n^{\prime}\right)}+g_{j}^{\left(n n^{\prime}\right)}$.

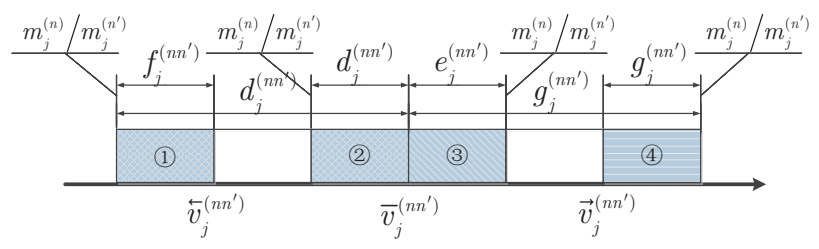

Fig. 1: Relationship between BPA Function and TIN

For TIN knowledge matrix, optimal BPA function can definitely fulfill all the constraint conditions with minimum total deviation. Especially, when total deviation is 0, BPA function could fulfill (6) completely, and then named TIN knowledge matrix is complete consistent in here. Combining with definition 7 , we propose objective function can be represented by the total deviation between BPA function $m_{j}^{(n)}\left(n=1, \cdots, N_{j}+1\right)$ and TIN knowledge matrix $\tilde{V}_{j}$ as objective function. The optimal BPA function determining model in attribute $c_{j}$ is as follows.

$$
\begin{aligned}
& \min \sigma_{j}=\sum_{\tilde{v}_{j}^{\left(n n^{\prime}\right)} \neq \varnothing} \alpha\left(d_{j}^{\left(n n^{\prime}\right)}+e_{j}^{\left(n n^{\prime}\right)}\right)+\sum_{\tilde{v}_{j}^{\left(n n^{\prime}\right)} \neq \varnothing} \beta\left(f_{j}^{\left(n n^{\prime}\right)}+g_{j}^{\left(n n^{\prime}\right)}\right) \\
& \text { s.t. }\left\{\begin{array}{l}
m_{j}^{\left(n^{\prime}\right)} \bar{v}_{j}^{\left(n n n^{\prime}\right)}-m_{j}^{(n)}-d_{j}^{\left(n n^{\prime}\right)}+e_{j}^{\left(n n^{\prime}\right)}=0, n \neq n^{\prime}, \bar{v}_{j}^{\left(n n^{\prime}\right)} \neq \varnothing ; \\
m_{j}^{(n)}+f_{j}^{\left(n n^{\prime}\right)} \geq m_{j}^{\left(n^{\prime}\right)} \overleftarrow{v}_{j}^{\left(n n^{\prime}\right)}, n \neq n^{\prime}, \overleftarrow{v}_{j}^{\left(n n^{\prime}\right)} \neq \varnothing ; \\
m_{j}^{(n)} \leq m_{j}^{\left(n^{\prime}\right)} \mathbf{v}_{j}^{\left(n \prime^{\prime}\right)}+g_{j}^{\left(n n^{\prime}\right)}, n \neq n^{\prime}, \mathbf{v}_{j}^{\left(n n^{\prime}\right)} \neq \varnothing ; \\
\sum_{n=1}^{N_{j}+1} m_{j}^{(n)}=1 ; m_{j}^{(n)} \geq 0, n=1, \cdots, N_{j}+1 ; \\
d_{j}^{\left(n n{ }^{\prime}\right)} e_{j}^{\left(n n^{\prime}\right)}=0, d_{j}^{\left(n n^{\prime}\right)}, e_{j}^{\left(n n^{\prime}\right)}, f_{j}^{\left(n n^{\prime}\right)}, g_{j}^{\left(n n^{\prime}\right)} \geq 0, n=1, \cdots, N_{j}+1 .
\end{array}\right.
\end{aligned}
$$

Where $\alpha$ and $\beta(\alpha+\beta=1)$ that separately represent relative importance level of deviation of TIN gravity center and deviation of two endpoints, and these two constants should be determined by experts' group. Since the gravity center reflects opinions of most experts, as usual we have $\alpha \geq \beta$ in general situation. First three constrains aim at make $m_{j}^{(n)} / m_{j}^{\left(n^{\prime}\right)}$ return to consistency area as shown in (6) by using deviation variables. The forth constraint is definition demand of BPA function in (1). The $d_{j}^{\left(n n^{\prime}\right)} e_{j}^{\left(n n^{\prime}\right)}=0$ of last restrain is for keeping $m_{j}^{(n)} / m_{j}^{\left(n^{\prime}\right)}$ at only one side of $\bar{v}_{j}^{\left(n n^{\prime}\right)}$ at same time, namely when it in area 1 and $2, d_{j}^{\left(n n^{\prime}\right)}>0$ and $e_{j}^{\left(n n^{\prime}\right)}=0$, but when it in area 3 and $4, e_{j}^{\left(n n^{\prime}\right)}>0$ and $d_{j}^{\left(n n^{\prime}\right)}=0$. 
Theorem 1. Determining BPA function model has optimal solution, and the consistency of TIN matrix will get worse as the value of optimal objective function is getting bigger. Proof.Let $m_{j}^{\prime(1)}, \cdots, m_{j}^{\prime(n)}$ be a random BPA function that satisfys $\sum_{n=1}^{N_{j}+1} m_{j}^{(n)}=1$ and $m_{j}^{(n)} \geq 0(\forall n)$. Obviously, set $m_{j}^{\prime(1)}, \cdots, m_{j}^{\prime(n)}$ as reference, there must be a group of deviation constants $d_{j}^{\prime\left(n n^{\prime}\right)}, e_{j}^{\prime\left(n n^{\prime}\right)}, f_{j}^{\prime\left(n n^{\prime}\right)}, g_{j}^{\prime\left(n n^{\prime}\right)}\left(\forall n, n^{\prime}\right)$ that satisfy (8a) or (8b). That is, there must be a feasible solution of determining BPA function model. As seen by the principle of optimality, when constrain (7) has feasible solution, the optimal solution will be at a vertex in a convex set originated from the linear constrains, so the BPA function determining model must have an optimal solution. We can utilize an arithmetic put forward by Takahito to acquire global optimal solution [19].

$$
\begin{aligned}
& \begin{cases}d_{j}^{\left(n n^{\prime}\right)}=m_{j}^{\prime\left(n^{\prime}\right)} \bar{v}_{j}^{(n)}-m_{j}^{\prime(n)}, e_{j}^{\left(n n^{\prime}\right)}=0, & n=1, \cdots, N_{j} ; \\
f_{j}^{\left(n n^{\prime}\right)} \geq m_{j}^{\prime\left(n^{\prime}\right)} \overleftarrow{v}_{j}^{(n)}-m_{j}^{\prime(n)}, & n=1, \cdots, N_{j} ; \quad(8 \mathrm{a}) \\
g_{j}^{\left(n n^{\prime}\right)} \geq m_{j}^{\prime\left(n^{\prime}\right)} \mathbf{v}_{j}^{(n)}-m_{j}^{\prime(n)}, & n=1, \cdots, N_{j} .\end{cases} \\
& \begin{cases}e_{j}^{\left(n n^{\prime}\right)}=-m_{j}^{\prime}{ }^{\left(n^{\prime}\right)} \bar{v}_{j}^{(n)}+m_{j}^{\prime(n)}, d_{j}^{\left(n n^{\prime}\right)}=0, & n=1, \cdots, N_{j} ; \\
f_{j}^{\left(n n^{\prime}\right)} \geq m_{j}^{\prime\left(n^{\prime}\right)} \overleftarrow{v}_{j}^{(n)}-m_{j}^{\prime(n)}, & n=1, \cdots, N_{j} ;(8 \mathrm{~b}) \\
g_{j}^{\left(n n^{\prime}\right)} \geq m_{j}^{\prime\left(n^{\prime}\right)} \mathbf{v}_{j}^{(n)}-m_{j}^{\prime(n)}, & n=1, \cdots, N_{j} .\end{cases}
\end{aligned}
$$

In addition, let optimal objective function value of BPA function determining model as $\tilde{\sigma}_{j}$, optimal solution as $\tilde{X}_{j}=\left\{\tilde{m}_{j}^{(n)}, \tilde{d}_{j}^{\left(n n^{\prime}\right)}, \tilde{e}_{j}^{\left(n n^{\prime}\right)}, \tilde{f}_{j}^{\left(n n^{\prime}\right)}, \tilde{g}_{j}^{\left(n n^{\prime}\right)} \mid \forall n, n^{\prime}\right\}$. Due to the rule $d_{j}^{\left(n n^{\prime}\right)}, e_{j}^{\left(n n^{\prime}\right)}, f_{j}^{\left(n n^{\prime}\right)}, g_{j}^{\left(n n^{\prime}\right)} \geq 0\left(\forall n, n^{\prime}\right)$ in restrain conditions, there must be $\tilde{\sigma}_{j} \geq 0$. When $\tilde{\sigma}_{j}=0$, known by the expression of objective function, there must be $\tilde{d}_{j}^{\left(n n^{\prime}\right)}, \tilde{e}_{j}^{\left(n n^{\prime}\right)}, \tilde{f}_{j}^{\left(n n^{\prime}\right)}, \tilde{g}_{j}^{\left(n n^{\prime}\right)}=0\left(\forall n, n^{\prime}\right)$. We can see from first three constrains that optimal solution $\tilde{m}_{j}^{(n)}(\forall n)$ must could fulfill relation in (6), which state TIN knowledge matrix has complete consistency. When $\tilde{\sigma}_{j}>0$, there must have non-zero positive solution. By this time optimal solution $\tilde{m}_{j}^{(n)}(\forall n)$ could not fulfill (6) completely, which state TIN knowledge matrix do not have complete consistency. For the monotonically increasing of objective function, as $\tilde{\sigma}_{j}$ gets higher, the non-zero positive solutions of $\tilde{d}_{j}^{\left(n n^{\prime}\right)}, \tilde{e}_{j}^{\left(n n^{\prime}\right)}, \tilde{f}_{j}^{\left(n n^{\prime}\right)}, \tilde{g}_{j}^{\left(n n^{\prime}\right)}\left(\forall n, n^{\prime}\right)$ are getting more and larger, the complete consistency of TIN knowledge matrix is getting worse. $\square$

\section{TIN knowledge matrix modified model}

TIN knowledge matrix is constructed by experts through discussion such that it contains judgment of subjective and experiential knowledge for the decision issue. However, the complexity of decision context and the finiteness of subjective cognition determine that it is not practical to get TIN matrix complete consistency [20], so more reasonable method is permitting the existence of inconformity, but this inconformity should be controlled in a certain scale. For the permitting degree problem of inconformity, we imitate the consistency threshold definition of Zhu Jianjun in 'Three-point Interval Number judgment matrix' [15] or we can set the value of threshold $\Delta_{j}$ proper motion by combining decision accuracy requirement.

Because of TIN knowledge matrix $\tilde{V}_{j}$ is a comprehensive deduction given by experts through discussion, we can infer that most information of $\tilde{V}_{j}$ is scientific and the inconformity is caused by individual and unreasonable judgment information. Therefore, to guarantee decision quality and enhancing decision efficiency, it is especially important to recognize unreasonable elements from $\tilde{V}_{j}$ and revise them, meanwhile guaranteeing that the ensemble information of TIN knowledge matrix is scientific. Specially, the optimal solution $\tilde{m}_{j}^{(n)}(\forall n)$ obtained from introducing $\tilde{V}_{j}$ to BPA determining model, is an optimal result describing overall inference information given by experts, comprehensively considering the containing information of all elements in TIN knowledge matrix. If $\tilde{m}_{j}^{(n)}(\forall n)$ is used as intermediation to revise TIN knowledge matrix, on one hand we can affirm the scientificalness of entire information in primary TIN knowledge matrix, on the other hand we can promote TIN knowledge matrix perfection based on original scientific information (see details in theorem 4).

Let element $\tilde{v}_{j}^{\left(n n^{\prime}\right)}=\left[\overleftarrow{v}_{j}^{\left(n n^{\prime}\right)}, \bar{v}_{j}^{\left(n n^{\prime}\right)}, \mathbf{v}_{j}^{\left(n n^{\prime}\right)}\right]$ in TIN knowledge matrix be revised as

$$
\left\{\begin{array}{l}
\bar{v}_{j}^{\prime \prime}\left(n n^{\prime}\right)=\bar{v}_{j}^{\left(n n^{\prime}\right)}+r_{j}^{\left(n n^{\prime}\right)}, \bar{v}_{j}^{\left(n n^{\prime}\right)} \neq \varnothing \\
\overleftarrow{v}_{j}^{\prime \prime\left(n n^{\prime}\right)}=\overleftarrow{v}_{j}^{\left(n n^{\prime}\right)}+s_{j}^{\left(n n^{\prime}\right)}, \bar{v}_{j}^{\left(n n^{\prime}\right)} \neq \varnothing \\
\mathbf{v}_{j}^{\prime \prime\left(n n^{\prime}\right)}=\mathbf{v}_{j}^{\left(n n^{\prime}\right)}+t_{j}^{\left(n n^{\prime}\right)}, \bar{v}_{j}^{\left(n n^{\prime}\right)} \neq \varnothing
\end{array}\right.
$$

Thereinto, $r_{j}^{\left(n n^{\prime}\right)}, s_{j}^{\left(n n^{\prime}\right)}, t_{j}^{\left(n n^{\prime}\right)}$ represent the revised range for $\bar{v}_{j}^{\left(n n^{\prime}\right)}, \overleftarrow{v}_{j}^{\left(n n^{\prime}\right)}, \mathbf{v}_{j}^{\left(n n^{\prime}\right)}$. We always wish that the consistency of revised matrix $\tilde{V}_{j}^{\prime \prime}$ would be better than original matrix $\tilde{V}_{j}$, the total deviation would be as small as possible. However, the decrease of total deviation might increase individual deviation; namely local individual deviation might increase, but the whole total deviation however decreases. Thus $r_{j}^{\left(n n^{\prime}\right)}, s_{j}^{\left(n n^{\prime}\right)}, t_{j}^{\left(n n^{\prime}\right)}$ above could be positive or negative.

In view of the process of experts' interactive discussion for realizing the cognition of one issue is not accomplished at once but a progressive procedure. The consistency of revised matrix $\tilde{V}_{j}^{\prime \prime}$ would be better than original $\tilde{V}_{j}$, which could guarantee the consistency requirement of TIN knowledge matrix by limited times' discussion. Here introduce parameter $\gamma_{j}$ to reflect the revised efficiency in consistency of TIN knowledge matrix. Let $\tilde{\sigma}^{\prime \prime} \leq \gamma \tilde{\sigma}$, since $\gamma_{j}$ is used for reducing 
deviation, then $\gamma_{j}<1$, and because the matrix could satisfy the requirement of consistency threshold through several times revision, then $\gamma_{j} \tilde{\sigma}_{j} \geq \Delta_{j}$. The specific value of parameter $\gamma_{j}$ in interval $\left[\Delta_{j} / \tilde{\sigma}_{j}, 1\right)$ is determined by experts group by comprehensively balancing revised quality and velocity. In addition, the inconformity in TIN knowledge matrix is caused by unreasonable individual deduction information, and the irrational point must be inconsistent with most experts' opinions. If set $\tilde{m}_{j}^{(n)}(\forall n)$ as whole information scientific standard of original TIN knowledge matrix, then the parameter that represent reasonable degree of elements in $\tilde{V}_{j}$ could be set as optimal solutions in BPA function determining model $\tilde{d}_{j}^{\left(n n^{\prime}\right)}, \tilde{e}_{j}^{\left(n n^{\prime}\right)}, \tilde{f}_{j}^{\left(n n^{\prime}\right)}, \tilde{g}_{j}^{\left(n n^{\prime}\right)}\left(\forall n, n^{\prime}\right)$. For instance, the greater the value of $\tilde{f}_{j}^{\left(n n^{\prime}\right)}$ is, the greater the irrational degree of $\overleftarrow{v}_{j}^{\left(n n^{\prime}\right)}$ is, vice versa. Apparently, in TIN knowledge matrix, the higher the irrational degree of element proposed to adjust is, the more scientific of revision is, meanwhile, the more efficient of regression consistent of TIN knowledge matrix is. On that account, for revising TIN knowledge matrix scientifically and efficiently, we construct theoretical revision model of TIN knowledge matrix (simplified as theory model) as follow:

$$
\begin{aligned}
& \min \phi_{j}= \sum_{\tilde{v}_{j}\left(n n^{\prime}\right) \neq \varnothing}\left[\left(\tilde{d}_{j}^{\left(n n^{\prime}\right)}+\tilde{e}_{j}^{\left(n n^{\prime}\right)}\right) r_{j}^{\left(n n^{\prime}\right)}\right]^{2}+\sum_{\overleftarrow{v}}\left(n n^{\prime}\right) \neq \varnothing \\
&\left.+\sum_{\mathbf{v}_{j}^{\left(n n^{\prime}\right)} \neq \varnothing}\left(\tilde{f}_{j}^{\left(n n^{\prime}\right)} s_{j}^{\left(n n^{\prime}\right)}\right)^{2} t_{j}^{\left(n n n^{\prime}\right)} t^{\left(n n^{\prime}\right)}\right)^{2} \\
& \text { s.t. }\left\{\begin{array}{l}
\tilde{m}_{j}^{(n)}\left(\bar{v}_{j}^{\left(n n^{\prime}\right)}+r_{j}^{\left(n n^{\prime}\right)}\right)-\tilde{m}_{j}^{(n)}-d_{j}^{\left(n n^{\prime}\right)}+e_{j}^{\left(n n^{\prime}\right)}=0, n \neq n^{\prime}, \bar{v}_{j}^{\left(n n^{\prime}\right)} \neq \varnothing ; \\
\tilde{m}_{j}^{(n)}+f_{j}^{\left(n n^{\prime}\right)} \geq \tilde{m}_{j}^{(n)}\left(\overleftarrow{v}_{j}^{\left(n n^{\prime}\right)}+s_{j}^{\left(n n^{\prime}\right)}\right), n \neq n^{\prime}, \overleftarrow{v}_{j}^{\left(n n^{\prime}\right)} \neq \varnothing ; \\
\tilde{m}_{j}^{(n)} \leq \tilde{m}_{j}^{\left(n n^{\prime}\right)}\left(\mathbf{v}_{j}^{\left(n n^{\prime}\right)}+t_{j}^{\left(n n^{\prime}\right)}\right)+g_{j}^{\left(n n^{\prime}\right)}, n \neq n^{\prime}, \mathbf{v}_{j}^{\left(n n^{\prime}\right)} \neq \varnothing ; \\
\sum_{\tilde{v}_{j}\left(n n^{\prime}\right) \neq \varnothing} \alpha\left(d_{j}^{\left(n n^{\prime}\right)}+e_{j}^{\left(n n^{\prime}\right)}\right)+\sum_{\tilde{v}_{j}^{\left(n n^{\prime}\right)} \neq \varnothing} \beta\left(f_{j}^{\left(n n^{\prime}\right)}+g_{j}^{\left(n n^{\prime}\right)}\right) \leq \gamma \tilde{\sigma}_{j} ; \\
d_{j}^{\left(n n^{\prime}\right)} e_{j}^{\left(n n^{\prime}\right)}=0, d_{j}^{\left(n n^{\prime}\right)}, e_{j}^{\left(n n^{\prime}\right)}, f_{j}^{\left(n n^{\prime}\right)}, g_{j}^{\left(n n^{\prime}\right)} \geq 0, n=1, \cdots, N_{j}+1 .
\end{array}\right.
\end{aligned}
$$

Thereinto, the effect of objective function is, during adjusting elements which have highest unreasonable degrees, by using minimum adjustment range and fastest revise velocity to make regression of matrix consistent. First three constrains make revised matrix $\tilde{V}_{j}^{\prime \prime}$ has complete consistency by introducing deviation variables. Forth constrain make revised matrix fulfill the adjusting require of consistency. The meaning of fifth constrain and each symbolic are as same as BPA function determining model.

Theoretical model is a quadratic programming problem that constrain conditions contain multiplication constrains. For solving and proving conveniently, we transform the model into a programming model with linear objective function as model (7). Specifically, firstly making a nonnegative variables transformation to $r_{j}^{\left(n n^{\prime}\right)}, s_{j}^{\left(n n^{\prime}\right)}, t_{j}^{\left(n n^{\prime}\right)}$ that represent the revision range in the matrix elements $\bar{v}_{j}^{\left(n n^{\prime}\right)}, \overleftarrow{v}_{j}^{\left(n n^{\prime}\right)}, \mathbf{v}_{j}^{\left(n n^{\prime}\right)}$. Namely

$$
\left\{\begin{array}{l}
r_{j}^{\left(n n^{\prime}\right)}=\mathbf{r}_{j}^{\left(n n^{\prime}\right)}-\overleftarrow{r}_{j}^{\left(n n^{\prime}\right)}, \mathbf{r}_{j}^{\left(n n^{\prime}\right)} \geq 0, \overleftarrow{r}_{j}^{\left(n n^{\prime}\right)} \geq 0, \mathbf{r}_{j}^{\left(n n^{\prime}\right)} \overleftarrow{\leftarrow}_{j}^{\left(n n^{\prime}\right)}=0 \\
s_{j}^{\left(n n^{\prime}\right)}=\mathbf{s}_{j}^{\left(n n^{\prime}\right)}-\overleftarrow{s}_{j}^{\left(n n^{\prime}\right)}, \mathbf{s}_{j}^{\left(n n^{\prime}\right)} \geq 0, \overleftarrow{s}_{j}^{\left(n n^{\prime}\right)} \geq 0, \mathbf{s}_{j}^{\left(n n^{\prime}\right)} \overleftarrow{s}_{j}^{\left(n n^{\prime}\right)}=0 \\
t_{j}^{\left(n n^{\prime}\right)}=\mathbf{t}_{j}^{\left(n n^{\prime}\right)}-\overleftarrow{t}_{j}^{\left(n n^{\prime}\right)}, \mathbf{t}_{j}^{\left(n n^{\prime}\right)} \geq 0, \overleftarrow{t}_{j}^{\left(n n^{\prime}\right)} \geq 0, \mathbf{t}_{j}^{\left(n n^{\prime}\right)} \overleftarrow{\leftarrow}_{j}^{\left(n n^{\prime}\right)}=0
\end{array}\right.
$$

Then, we can construct a calculation model could solve TIN knowledge matrix theoretical revision model (simplified calculation model). The specific expression as follow:

$$
\begin{aligned}
& \min \varphi_{j}=\sum_{\tilde{v}_{j}^{\left(n n^{\prime}\right)} \neq \varnothing}\left[\left(\tilde{d}_{j}^{\left(n n^{\prime}\right)}+\tilde{e}_{j}^{\left(n n^{\prime}\right)}\right)\left(\mathbf{r}_{j}^{\left(n n^{\prime}\right)}+\overleftarrow{r}_{j}^{\left(n n^{\prime}\right)}\right)\right] \\
& +\sum_{\overleftarrow{v}_{j}^{\left(n n^{\prime}\right)} \neq \varnothing}\left[\tilde{f}_{j}^{\left(n n^{\prime}\right)}\left(\mathbf{s}_{j}^{\left(n n^{\prime}\right)}+\overleftarrow{s}_{j}^{\left(n n^{\prime}\right)}\right)\right] \\
& +\sum_{\mathbf{v}_{j}^{\left(n n^{\prime}\right)} \neq \varnothing}\left[\tilde{g}_{j}^{\left(n n^{\prime}\right)}\left(\mathbf{t}_{j}^{\left(n n^{\prime}\right)}+\overleftarrow{t}_{j}^{\left(n n^{\prime}\right)}\right)\right]
\end{aligned}
$$

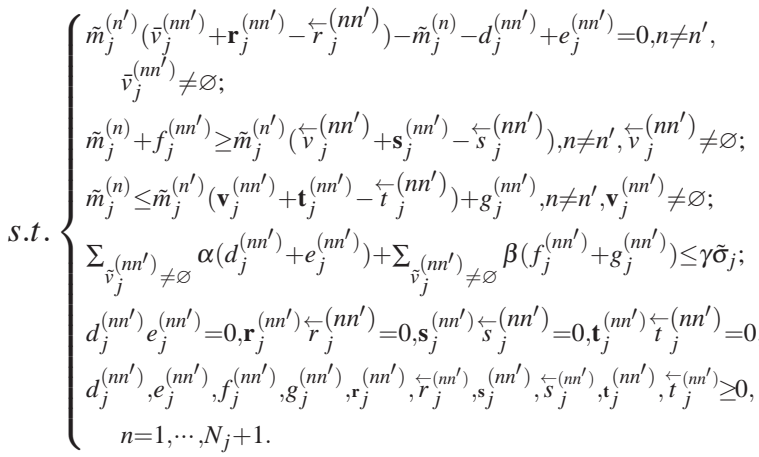

Theorem 2. Calculation model has optimal solution.

Proof.Similar to proving principle in theorem 1, provided we can prove that the constraints in calculation model have feasible solutions, we can infer that this model must have optimal solution, and then can use Takahito's arithmetic to acquire the global optimal solution. Obviously, when $\mathbf{r}_{j}^{\left(n n^{\prime}\right)}=\overleftarrow{r}_{j}^{\left(n n^{\prime}\right)}=0, \mathbf{s}_{j}^{\left(n n^{\prime}\right)}=\overleftarrow{s}_{j}^{\left(n n^{\prime}\right)}=0$ $\mathbf{t}_{j}^{\left(n n^{\prime}\right)}=\overleftarrow{t}_{j}^{\left(n n^{\prime}\right)}=0$, calculation model and theoretical model are completely equivalent. Thus the optimal solution $\tilde{X}_{j}=\left\{\tilde{m}_{j}^{(n)}, \tilde{d}_{j}^{\left(n n^{\prime}\right)}, \tilde{e}_{j}^{\left(n n^{\prime}\right)}, \tilde{f}_{j}^{\left(n n^{\prime}\right)}, \tilde{g}_{j}^{\left(n n^{\prime}\right)} \mid \forall n, n^{\prime}\right\}$ in BPA determining model could satisgy all constrains of calculation model, so they are a feasible solution of calculation model. $\square$

Theorem 3. Optimal solution of calculation model is the optimal solution of theoretical model.

Proof.Let the optimal solution of calculation model is $Y_{j}^{\prime}=\left\{\mathbf{r}_{j}^{\prime\left(n n^{\prime}\right)}, \overleftarrow{r}_{j}^{\prime\left(n n^{\prime}\right)}, \mathbf{s}_{j}^{\prime\left(n n^{\prime}\right)}, \overleftarrow{s}_{j}^{\prime\left(n n^{\prime}\right)}, \mathbf{t}_{j}^{\prime\left(n n^{\prime}\right)}, \overleftarrow{t}_{j}^{\prime\left(n n^{\prime}\right)}, d_{j}^{\prime\left(n n^{\prime}\right)}\right.$, $\left.e_{j}^{\prime\left(n n^{\prime}\right)}, f_{j}^{\prime\left(n n^{\prime}\right)}, g_{j}^{\prime\left(n n^{\prime}\right)} \mid \forall n, n^{\prime}\right\}$, optimal value of objective function is $\varphi_{j}^{\prime}$. The optimal solution is theoretical model is $Y_{j}^{\prime \prime}=\left\{r_{j}^{\prime \prime\left(n n^{\prime}\right)}, s_{j}^{\prime \prime\left(n n^{\prime}\right)}, t_{j}^{\prime \prime\left(n n^{\prime}\right)}, d_{j}^{\prime \prime\left(n n^{\prime}\right)}, e_{j}^{\prime \prime\left(n n^{\prime}\right)}, f_{j}^{\prime \prime\left(n n^{\prime}\right)}\right.$, $\left.g_{j}^{\prime \prime\left(n n^{\prime}\right)} \mid \forall n, n^{\prime}\right\}$, optimal value of objective function is $\phi_{j}^{\prime \prime}$. Suppose the optimal solution of calculation model is not the optimal solution of theoretical model, then one of 
following situations must have existed: $\left|r_{j}^{\prime \prime\left(n n^{\prime}\right)}\right|<\mathbf{r}_{j}^{\prime\left(n n^{\prime}\right)}$ $+\overleftarrow{r}_{j}^{\prime\left(n n^{\prime}\right)},\left|s_{j}^{\prime \prime\left(n n^{\prime}\right)}\right|<\mathbf{s}_{j}^{\prime\left(n n^{\prime}\right)}+\overleftarrow{s}_{j}^{\prime\left(n n^{\prime}\right)},\left|t_{j}^{\prime \prime\left(n n^{\prime}\right)}\right|<\mathbf{t}_{j}^{\prime\left(n n^{\prime}\right)}$ $+\overleftarrow{t}_{j}^{\prime\left(n n^{\prime}\right)}$. Known from definition below, $r_{j}^{\prime \prime\left(n n^{\prime}\right)}=\mathbf{r}_{j}^{\prime \prime\left(n n^{\prime}\right)}$ $-\overleftarrow{r}_{j}^{\prime \prime\left(n n^{\prime}\right)}, \quad s_{j}^{\prime \prime\left(n n^{\prime}\right)}=\mathbf{s}_{j}^{\prime \prime\left(n n^{\prime}\right)}-\overleftarrow{s}_{j}^{\prime \prime\left(n n^{\prime}\right)}, \quad t_{j}^{\prime \prime\left(n n^{\prime}\right)}=\mathbf{t}_{j}^{\prime \prime\left(n n^{\prime}\right)}$ $-\overleftarrow{t}_{j}^{\prime \prime\left(n n^{\prime}\right)}$. Since $\mathbf{r}_{j}^{\prime \prime\left(n n^{\prime}\right)}, \overleftarrow{r}_{j}^{\prime \prime\left(n n^{\prime}\right)} \geq 0$ and $\mathbf{r}_{j}^{\prime \prime\left(n n^{\prime}\right)} \overleftarrow{r}_{j}^{\prime \prime\left(n n^{\prime}\right)}=0$

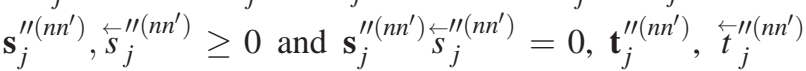
$\geq 0$ and $\mathbf{t}_{j}^{\prime \prime\left(n n^{\prime}\right)} \overleftarrow{t}_{j}^{\prime \prime\left(n n^{\prime}\right)}=0$, then $\mathbf{r}_{j}^{\prime \prime\left(n n^{\prime}\right)}+\overleftarrow{r}_{j}^{\prime \prime\left(n n^{\prime}\right)}<\mathbf{r}_{j}^{\prime\left(n n^{\prime}\right)}$ $+\overleftarrow{r}_{j}^{\prime\left(n n^{\prime}\right)}, \mathbf{s}_{j}^{\prime \prime\left(n n^{\prime}\right)}+\overleftarrow{s}_{j}^{\prime \prime\left(n n^{\prime}\right)}<\mathbf{s}_{j}^{\prime\left(n n^{\prime}\right)}+\overleftarrow{s}_{j}^{\prime\left(n n^{\prime}\right)}, \mathbf{t}_{j}^{\prime \prime\left(n n^{\prime}\right)}+\overleftarrow{t}_{j}^{\prime \prime\left(n n^{\prime}\right)}$ $<\mathbf{t}_{j}^{\prime\left(n n^{\prime}\right)}+\overleftarrow{t}_{j}^{\prime\left(n n^{\prime}\right)}$. This time, taking $\mathbf{r}_{j}^{\prime \prime\left(n n^{\prime}\right)}, \overleftarrow{r}_{j}^{\prime \prime\left(n n^{\prime}\right)}$, $\mathbf{s}_{j}^{\prime \prime\left(n n^{\prime}\right)}, \overleftarrow{s}_{j}^{\prime \prime\left(n n^{\prime}\right)}, \mathbf{t}_{j}^{\prime \prime\left(n n^{\prime}\right)}, \overleftarrow{t}_{j}^{\prime \prime\left(n n^{\prime}\right)}$ into objective function of calculation model to get $\varphi_{j}^{\prime \prime}$, the value must less than $\varphi_{j}^{\prime}$ corresponding to $\mathbf{r}_{j}^{\prime\left(n n^{\prime}\right)}, \overleftarrow{r}_{j}^{\prime\left(n n^{\prime}\right)}, \mathbf{s}_{j}^{\prime\left(n n^{\prime}\right)}, \overleftarrow{s}_{j}^{\prime\left(n n^{\prime}\right)}, \mathbf{t}_{j}^{\prime\left(n n^{\prime}\right)}$, $\overleftarrow{t}_{j}^{\prime\left(n n^{\prime}\right)}$. In the other words, another value of objective function smaller than $\varphi_{j}^{\prime}$ is existing, so this contradicts with the fact that $\varphi_{j}^{\prime}$ is the optimal objective function value of calculation model, then the assuming above is false.

Theorem 4. Consistency of Revised TIN knowledge matrix $\tilde{V}_{j}^{\prime \prime}$ is superior to original matrix $\tilde{V}_{j}$.

Proof.Using optimal solution $\left\{\mathbf{r}_{j}^{\prime\left(n n^{\prime}\right)}, \overleftarrow{r}_{j}^{\prime\left(n n^{\prime}\right)}, \mathbf{s}_{j}^{\prime\left(n n^{\prime}\right)}\right.$, $\left.\overleftarrow{s}_{j}^{\prime\left(n n^{\prime}\right)}, \mathbf{t}_{j}^{\prime\left(n n^{\prime}\right)}, \overleftarrow{t}_{j}^{\prime\left(n n^{\prime}\right)} \mid \forall n, n^{\prime}\right\} \in Y_{j}^{\prime}$ to revise original knowledge matrix $\tilde{V}_{j}$ as shown in (9) and (11) to get $\tilde{V}_{j}^{\prime \prime}$, then the optimal solution $\left\{d_{j}^{\prime\left(n n^{\prime}\right)}, e_{j}^{\prime\left(n n^{\prime}\right)}, f_{j}^{\prime\left(n n^{\prime}\right)}, g_{j}^{\prime\left(n n^{\prime}\right)}\right.$ $\left.\mid \forall n, n^{\prime}\right\} \in Y^{\prime}$ of elements and calculation model have to fulfill

$$
\left\{\begin{array}{l}
\tilde{m}_{j}^{\left(n^{\prime}\right)} \bar{v}_{j}^{\prime \prime\left(n n^{\prime}\right)}-\tilde{m}_{j}^{(n)}-d_{j}^{\prime\left(n n^{\prime}\right)}+e_{j}^{\prime\left(n n^{\prime}\right)}=0, n \neq n^{\prime},,_{j}^{\prime \prime\left(n n^{\prime}\right)} \neq \varnothing ; \\
\tilde{m}_{j}^{(n)}+f_{j}^{\prime\left(n n^{\prime}\right)} \geq \tilde{m}_{j}^{\left(n^{\prime}\right) \overleftarrow{v}_{j}^{\prime \prime}\left(n n^{\prime}\right)}, n \neq n^{\prime}, \overleftarrow{v}_{j}^{\prime \prime\left(n n^{\prime}\right)} \neq \varnothing ; \\
\tilde{m}_{j}^{(n)} \leq \tilde{m}_{j}^{\left(n^{\prime}\right)} \mathbf{v}_{j}^{\prime \prime\left(n n^{\prime}\right)}+g_{j}^{\prime\left(n n^{\prime}\right)}, n \neq n^{\prime}, \mathbf{v}_{j}^{\prime \prime\left(n n^{\prime}\right)} \neq \varnothing ; \\
\sum_{\tilde{v}_{j}^{\prime \prime\left(n n^{\prime}\right)} \neq \varnothing} \alpha\left(d_{j}^{\prime\left(n n^{\prime}\right)}+e_{j}^{\prime\left(n n^{\prime}\right)}\right)+\sum_{\tilde{v}_{j}^{\prime \prime}\left(n n^{\prime}\right)} \neq \varnothing{\left(f_{j}^{\prime}\left(n n^{\prime}\right)\right.}+g_{j}^{\prime}\left(n n^{\prime}\right) \leq \gamma \tilde{\sigma}_{j} ; \\
d_{j}^{\prime\left(n n^{\prime}\right)} e_{j}^{\prime\left(n n^{\prime}\right)}=0, d_{j}^{\prime\left(n n^{\prime}\right)}, e_{j}^{\prime\left(n n^{\prime}\right)}, f_{j}^{\prime\left(n n^{\prime}\right)}, g_{j}^{\prime\left(n n^{\prime}\right)} \geq 0, n=1, \cdots, N_{j}+1 .
\end{array}\right.
$$

Additionally, since $\tilde{m}_{j}^{(n)}(\forall n)$ is the optimal solution of BPA determining model, it has to fulfill $\tilde{m}_{j}^{(n)} \geq 0(\forall n)$ and $\sum_{n=1}^{N_{j}+1} \tilde{m}_{j}^{(n)}=1$. Contrasting contraints in (13) and (7), we can find that $\tilde{m}_{j}^{(n)}, d_{j}^{\prime\left(n n^{\prime}\right)}, e_{j}^{\prime\left(n n^{\prime}\right)}, f_{j}^{\prime\left(n n^{\prime}\right)}, g_{j}^{\prime\left(n n^{\prime}\right)}\left(\forall n, n^{\prime}\right)$ is a feasible solution by taking $\tilde{V}_{j}^{\prime \prime}$ into BPA determining model. Learned from the fourth constrain, the feasible solution corresponding to $\tilde{m}_{j}^{(n)}$ have to fulfill $\tilde{\sigma}_{j}^{\prime}$ $=\sum_{\hat{v}_{j}^{\left(n n^{\prime}\right)} \neq \varnothing} \alpha\left(d_{j}^{\prime\left(n n^{\prime}\right)}+e_{j}^{\prime\left(n n^{\prime}\right)}\right)+\sum_{\hat{v}_{j}^{\prime\left(n n^{\prime}\right)} \neq \varnothing} \beta\left(f_{j}^{\prime\left(n n^{\prime}\right)}\right.$ $\left.+g_{j}^{\prime\left(n n^{\prime}\right)}\right) \leq \gamma \tilde{\sigma}_{j}$. What's more, due to $r \in\left[\Delta_{j} / \tilde{\sigma}_{j}, 1\right)$, then $\tilde{\sigma}_{j}^{\prime} \leq \tilde{\sigma}_{j}$. According to principle of optimality, the optimal solution and optimal value of objective function by taking
$\tilde{V}_{j}^{\prime \prime}$ into BPA function determining model have to be superior to feasible solution and corresponding objective function value. The feasible solution could fulfill $\tilde{\sigma}_{j}^{\prime} \leq \tilde{\sigma}_{j}$, so the optimal solution must fulfill $\tilde{\sigma}_{j}^{\prime} \leq \tilde{\sigma}_{j}$.

\section{Intelligent Decision-making Process}

The cognition level of experts' group is getting more and more increasing during the interactive discussion process, so the TIN knowledge matrix is gaining on consistency threshold through continuing revision. During the process of discussion and revision, the BPA function determining model and TIN knowledge matrix modified model could not only define the discussion issues ,but also could guide the revising direction for experts group. Model above could be solved expediently by using computer with object-oriented programming techniques, and the solutions could help experts' group develop interactive discussion, information extraction, decision-making with high quality and high efficiency, by which could realize intelligent interaction and intelligent decision in human-machine context. Combining decision thought of nascent DS/AHP method and models and theorem suggested this paper, we can construct intelligent decision thought and decision procedures of TIN-DS/AHP as follow.

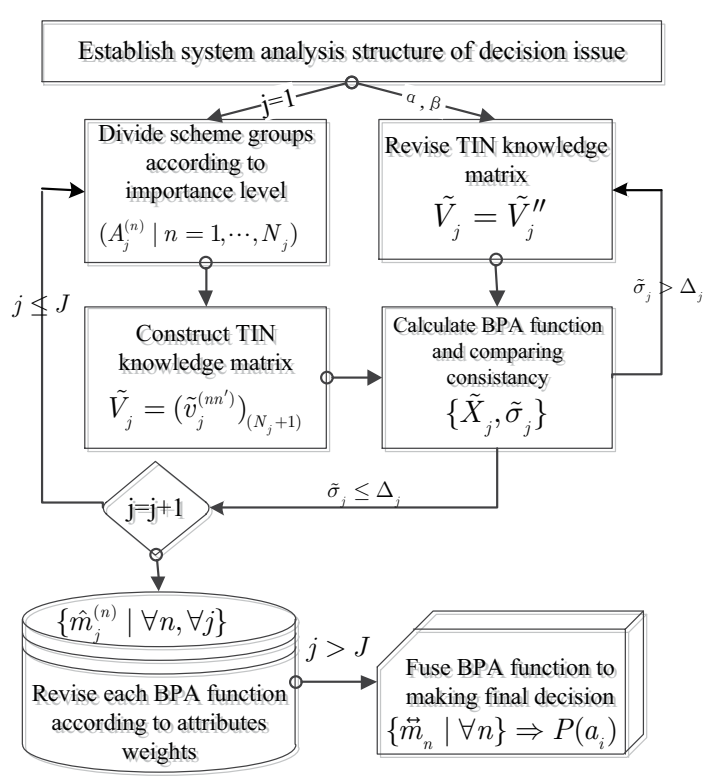

Fig. 2: Intelligent decision thought

Step 1: Establish system analysis structure of decision issue. Experts' group applies attributes $\left\{c_{1}\right.$, $\left.\cdots, c_{J}\right\}$ to evaluate ranking of alternatives; they determine the weights of attributes as $\left\{w_{j} \mid \Sigma_{j}\right.$ 
$\left.w_{j}=1, w_{j} \geq 0, j=1, \cdots, J\right\}$ through discussion, and then set the relatively importance levels $\alpha$ and $\beta(\alpha, \beta>0 ; \alpha+\beta=1)$ of gravity point deviation comparing with two vertexes in TIN and consistency threshold of TIN knowledge matrix. Finally methodize information below can acquire system analysis structure similar with AHP hierarchical structure (reference as Fig. 3 follow).

Step 2: Let $j=1$. The discussion object of experts' group is defined as attribute $c_{1}$.

Step 3: Divide alternative groups according to importance level. On attribute $c_{j}$, experts' group divides all the alternatives into a number of alternative groups $A_{j}^{(n)}, n=1, \cdots, N_{j}$ based on knowledge and experience. Any two alternative groups won't contain same alternatives $\left(A_{j}^{(n)} \cap A_{j}^{\left(n^{\prime}\right)}=\varnothing\right.$, $n \neq n^{\prime}$ ), and all the alternatives of every alternative group have same importance level. This dividing alternative group method could realize actually. If two alternative groups have same importance degree, then they can be merged as one group.

Step 4: Construct TIN knowledge matrix with communication and discussion. On attribute $c_{j}$, according to importance level of alternative group $A_{j}^{(n)}$ relative to $A_{j}^{\left(n^{\prime}\right)}\left(n \neq n^{\prime}\right)$ or Frame of Discernment $\Theta$, experts' group selects one or several alternative groups to discuss and gives deduction value independently based on 1-9 scale. When the distribution probability of some deducing value reaches particular threshold $\delta$, regarding this value as most likely value $\bar{v}_{j}^{\left(n n^{\prime}\right)}$, otherwise illustrate that experts' opinions are too disperse, need to be re-examined and discussed again, until they reach the threshold. After discussion all the experts give the most optimistic value and the most pessimistic value as maximum $\mathbf{v}_{j}^{\left(n n^{\prime}\right)}$ and minimum $\overleftarrow{v}_{j}^{\left(n n^{\prime}\right)}$ in TIN. Then combine and arrange $\bar{v}_{j}^{\left(n n^{\prime}\right)}, \mathbf{v}_{j}^{\left(n n^{\prime}\right)}, \overleftarrow{v}_{j}^{\left(n n^{\prime}\right)}$ getting from discussion based on definition 6 to obtain TIN deduction value $\tilde{v}_{j}^{\left(n n^{\prime}\right)}=\left[\overleftarrow{v}_{j}^{\left(n n^{\prime}\right)}, \bar{v}_{j}^{\left(n n^{\prime}\right)}, \mathbf{v}_{j}^{\left(n n^{\prime}\right)}\right]$ on attribute $c_{j}$ and TIN knowledge matrix $\tilde{V}_{j}$.

Step 5: Calculate BPA function and compare consistency. Taking TIN knowledge matrix $\tilde{V}_{j}$ into BPA determining model as shown in (7), solve the optimal objective function value $\tilde{\sigma}_{j}$ and optimal solution

$\tilde{X}_{j}=\left\{\tilde{m}_{j}^{(n)}, \tilde{d}_{j}^{\left(n n^{\prime}\right)}, \tilde{e}_{j}^{\left(n n^{\prime}\right)}, \tilde{f}_{j}^{\left(n n^{\prime}\right)}, \tilde{g}_{j}^{\left(n n^{\prime}\right)} \mid \forall n, n^{\prime}\right\} \quad$ of model. If $\tilde{\sigma}_{j}>\Delta_{j}$, stating that $\tilde{V}_{j}$ could not fulfill consistency, need to be revised, turn to step 6. If $\tilde{\sigma}_{j} \leq \Delta_{j}$, stating $\tilde{V}_{j}$ could fulfill consistency, then turn to step 7.

Step 6: Revise TIN knowledge matrix. Calculate the ratio $\Delta_{j} / \tilde{\sigma}_{j}$ of consistency threshold $\Delta_{j}$ and total deviation $\tilde{\sigma}_{j}$ of TIN knowledge matrix $\tilde{V}_{j}$, and then determine revision efficient parameter $\gamma_{j}\left(\gamma_{j} \in\left[\Delta_{j} / \tilde{\sigma}_{j}, 1\right)\right)$ through comprehensively balancing revising quality and revising velocity. Taking $\gamma_{j}, \tilde{V}_{j}$ and $\tilde{X}_{j}=\left\{\tilde{m}_{j}^{(n)}, \tilde{d}_{j}^{\left(n n^{\prime}\right)}, \tilde{e}_{j}^{\left(n n^{\prime}\right)}, \tilde{f}_{j}^{\left(n n^{\prime}\right)}\right.$, $\left.\tilde{g}_{j}^{\left(n n^{\prime}\right)} \mid \forall n, n^{\prime}\right\}$ into calculating model in (12), solve model to get optimal solution $Y_{j}^{\prime}=\left\{y_{j}^{\prime\left(n n^{\prime}\right)} \mid \mathbf{r}_{j}^{\prime\left(n n^{\prime}\right)}\right.$, $\overleftarrow{r}_{j}^{\prime\left(n n^{\prime}\right)}, \mathbf{s}_{j}^{\prime\left(n n^{\prime}\right)}, \overleftarrow{s}_{j}^{\prime\left(n n^{\prime}\right)}, \mathbf{t}_{j}^{\prime\left(n n^{\prime}\right)}, \overleftarrow{t}_{j}^{\prime\left(n n^{\prime}\right)}, d_{j}^{\prime\left(n n^{\prime}\right)}, e_{j}^{\prime\left(n n^{\prime}\right)}$, $\left.f_{j}^{\prime\left(n n^{\prime}\right)}, g_{j}^{\prime\left(n n^{\prime}\right)}, \forall n, n^{\prime}\right\}$. For all the elements $y_{j}^{\prime\left(n n^{\prime}\right)}$ $>0$, treat TIN corresponding to $y_{j}^{\prime\left(n n^{\prime}\right)}$ as discussing object, treat value of $y_{j}^{\prime\left(n n^{\prime}\right)}$ as revision reference, revise $\tilde{V}_{j}$ to $\tilde{V}_{j}^{\prime \prime}$ through discussion by experts' group, and let $\tilde{V}_{j}=\tilde{V}_{j}^{\prime \prime}$, turn to step 5 .

Step 7: Let $j=j+1$. Turn discussing objects from $c_{j}$ to $c_{j+1}$. If $j \leq J$, state that there still have attributes need to be discussed and constructing TIN knowledge matrix, turn step 3. If $j>J$, state that TIN knowledge matrix has been constructed TIN knowledge matrix on all the attributes, then turn to step 8 .

Step 8: Revise each BPA function according to attribute weights. Attribute weights represent relative importance level of specific origin decision information to decision issue. Imitate solving method in pertinent literature, let ratio that between specific attribute weight corresponding to maximum attribute weight be discount rate that revising BPA function under this attribute, and assign information loss in discount as unknown and uncertain (Frame of Discernment). Then the revised BPA function $\hat{m}_{j}^{(n)}$ on attribute $c_{j}$ could be determined as follows.

$$
\hat{m}_{j}^{(n)}= \begin{cases}\frac{w_{j} \tilde{m}_{j}^{(n)}}{\max \left\{w_{j} \mid j=1, \cdots J\right\}}, & n=1, \cdots, N_{j} \\ 1-\sum_{n=1}^{N_{j}} \frac{w_{j} \tilde{m}_{j}^{(n)}}{\max \left\{w_{j} \mid j=1, \cdots J\right\}}, & n=N_{j}+1\end{cases}
$$

Step 9: Fuse BPA function for making final decision. Treating every attribute as independent evidence source, use Dempster rule to fuse BPA function $\hat{m}_{j}^{(n)}$ of all the attributes, getting comprehensive BPA function $\left\{\overleftrightarrow{m}_{n} \mid n=1, \cdots, N\right\}$. Based on comprehensive BPA function and according to definition 5 to calculate Pignistic probability $P\left(a_{i}\right), i=1, \cdots, I$, corresponding to every alternative, then realize the ranking for all the alternatives.

\section{Numerical comparative analyses}

Imitating example put forward by Beynon, suppose that a certain university desires to apply attributes $\left\{c_{1}, c_{2}, c_{3}\right\}$ to 
comprehensively evaluate textbooks $\left\{a_{1}, \cdots, a_{10}\right\}$, experts' group $\left\{e_{1}, \cdots, e_{10}\right\}$ is built by teachers engaged in this mayor. Let experts' group infers alternative group according to importance level on every attribute as shown in Fig. 3, the relative importance level of deviation in TIN gravity center and two vertexes are $\alpha=0.7$ and $\beta=0.3$, consistency threshold of TIN knowledge matrix is $\Delta_{j}=0.25$. Based on the assumption that standard BPA function is existing, we will respectively use nascent DS/AHP method (short as nascent method) and proposed method in this paper (short as proposed method) to solve decision issue, for proving scientific validity and practical feasibility.

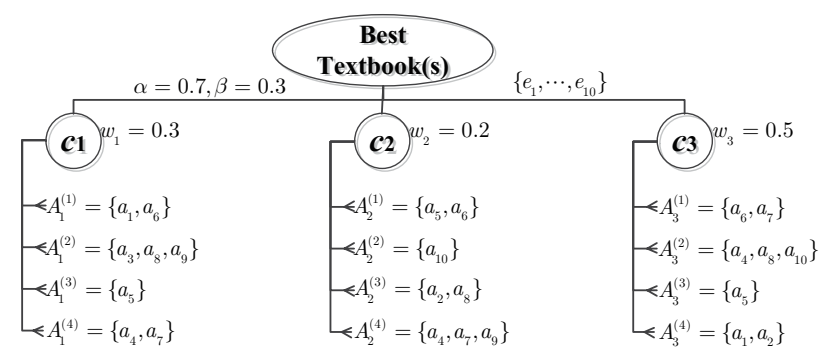

Fig. 3: Alternative groups deducing diagram

For the comparability of proposed method and nascent method, suppose there is a standard BPA function (namely the credible degree known in advance to every alternative group and Frame of Discernment, this credible degree could fulfill constrains in (1)) on every attribute, see details in line 2 of Table 1. Standard BPA function for one thing is used for generating anolog data of nascent method and proposed method, for the other thing the combining result is a reference standard for measuring merits of two methods. According to (14), by using attribute weights $\left(w_{1}=0.3, w_{2}=0.2, w_{3}=0.5\right)$ to revise standard BPA function, and then drag revised BPA function on all the attributes to Dempster rule in (2) to get comprehensive BPA function. Finally getting the merits ranking of every alternatives (standard ranking) by calculating Pignistic probability according to definition 5, see details in Table 2 Line 1-6.

For the data generating problem in nascent method, based on standard BPA function in Table 1, according to $\breve{v}_{j}^{(n)}=m_{j}\left(A_{j}^{(n)}\right) / m_{j}(\Theta)$, constructing importance level deduce value of alternative group $A_{j}^{(n)}$ corresponding to $\Theta, n=1, \cdots, 4, j=1,2,3$. Due to the finiteness of subjective deduce ability of experts' group, for imitating the obtaining result of deduce information in reality, we treat $\breve{v}_{j}^{(n)}$ as center to do random dereferencing and INTPART in fluctuating interval $\left[\breve{v}_{j}^{(n)}-2, \breve{v}_{j}^{(n)}+2\right]$. And due to the elements in traditional knowledge matrix is used of 2-6 scale; we control the extremums of random integers above in 2-6 scale. Process above could be realized by using random function, integral function and logic function in EXCEL, namely $v_{j}^{(n)}=\operatorname{round}\left(\breve{v}_{j}^{(n)}\right.$ $-2+4 * \operatorname{rand}(), 0)$ and $i f\left(v_{j}^{(n)}>6,6, i f\left(v_{j}^{(n)}<2\right.\right.$, $\left.\left.2, v_{j}^{(n)}\right)\right)$. Draging importance level deducing value $v_{j}^{(n)}$ of alternative group $A_{j}^{(n)}$ corresponding to $\Theta$ getting from process above into definition 4 could get imitate knowledge matrix roots from standard BPA function with fixed fluctuant, see details in (15). On this basis, we could realize transition from knowledge matrix to BPA function in nascent method according to (16). Then we can realize merits ranking for all the alternatives by using Dempster rule and Pignistic probability definition, see details in Table 2 Line $7-12$.

$$
\begin{aligned}
& V_{1}=\left[\begin{array}{ccccc}
1 & 0 & 0 & 0 & 5 \\
0 & 1 & 0 & 0 & 6 \\
0 & 0 & 1 & 0 & 4 \\
0 & 0 & 0 & 1 & 3 \\
1 / 5 & 1 / 6 & 1 / 4 & 1 / 3 & 1
\end{array}\right], \\
& V_{2}=\left[\begin{array}{ccccc}
1 & 0 & 0 & 0 & 5 \\
0 & 1 & 0 & 0 & 4 \\
0 & 0 & 1 & 0 & 3 \\
0 & 0 & 0 & 1 & 2 \\
1 / 5 & 1 / 4 & 1 / 3 & 1 / 2 & 1
\end{array}\right],
\end{aligned}
$$

$$
V_{3}=\left[\begin{array}{ccccc}
1 & 0 & 0 & 0 & 6 \\
0 & 1 & 0 & 0 & 4 \\
0 & 0 & 1 & 0 & 2 \\
0 & 0 & 0 & 1 & 3 \\
1 / 6 & 1 / 4 & 1 / 2 & 1 / 3 & 1
\end{array}\right]
$$

$\hat{m}_{j}^{(n)}= \begin{cases}v_{j}^{(n)} w_{j} /\left(\sum_{n=1}^{N_{j}} v_{j}^{(n)} w_{j}+\sqrt{N_{j}}\right), & n=1, \cdots, N_{j} \\ \sqrt{N_{j}} /\left(\sum_{n=1}^{N_{j}} v_{j}^{(n)} w_{j}+\sqrt{N_{j}}\right), & n=N_{j}+1 .\end{cases}$

For the anolog data generation problem in this paper, it not only need to base on importance level deducing value $\breve{v}_{j}^{(n \Theta)}=m_{j}\left(A_{j}^{(n)}\right) / m_{j}(\Theta)$ of standard BPA function obtaining alternative group $A_{j}^{(n)}$ corresponding to $\Theta$, but also need to obtain importance level deduce value $\breve{v}_{j}^{\left(n n^{\prime}\right)}$ $=m_{j}\left(A_{j}^{(n)}\right) / m_{j}\left(A_{j}^{\left(n^{\prime}\right)}\right)$ between some alternative groups $\left(A_{j}^{(n)}\right.$ and $\left.A_{j}^{\left(n^{\prime}\right)}, n \neq n^{\prime}\right)$. The generating processes of imitating deduce value above is basically identical with nascent method; the difference is the element $\tilde{v}_{j}^{\left(n n^{\prime}\right)}$ of TIN knowledge matrix includes minimum $\overleftarrow{v}_{j}^{\left(n n^{\prime}\right)}$, gravity center $\bar{v}_{j}^{\left(n n^{\prime}\right)}$, and maximum $\mathbf{v}_{j}^{\left(n n^{\prime}\right)}$. So generating a random 1-9 scale value in the interval $\left[\breve{v}_{j}^{\left(n n^{\prime}\right)}-1, \breve{v}_{j}^{\left(n n^{\prime}\right)}\right.$ $+1]$, treat it as $\bar{v}_{j}^{\left(n n^{\prime}\right)}$, then generating two random 1-9 scale value in intervals $\left[\bar{v}_{j}^{\left(n n^{\prime}\right)}-1, \bar{v}_{j}^{\left(n n^{\prime}\right)}\right]$ and $\left[\bar{v}_{j}^{\left(n n^{\prime}\right)}, \bar{v}_{j}^{\left(n n^{\prime}\right)}\right.$ 
Table 1: BPA function correlation table

\begin{tabular}{lccccccccccccccc}
\hline & $A_{1}^{(1)}$ & $A_{1}^{(2)}$ & $A_{1}^{(3)}$ & $A_{1}^{(4)}$ & $\Theta$ & $A_{2}^{(1)}$ & $A_{2}^{(2)}$ & $A_{2}^{(3)}$ & $A_{2}^{(4)}$ & $\Theta$ & $A_{3}^{(1)}$ & $A_{3}^{(2)}$ & $A_{3}^{(3)}$ & $A_{3}^{(4)}$ & $\Theta$ \\
\hline Standard BPA & 0.35 & 0.30 & 0.20 & 0.10 & 0.05 & 0.30 & 0.25 & 0.20 & 0.15 & 0.10 & 0.40 & 0.25 & 0.15 & 0.13 & 0.07 \\
Nascent BPA & 0.21 & 0.21 & 0.21 & 0.14 & 0.23 & 0.12 & 0.18 & 0.06 & 0.06 & 0.59 & 0.33 & 0.22 & 0.06 & 0.17 & 0.22 \\
Proposed BPA & 0.32 & 0.31 & 0.21 & 0.10 & 0.05 & 0.33 & 0.26 & 0.22 & 0.13 & 0.07 & 0.39 & 0.26 & 0.15 & 0.13 & 0.07 \\
\hline
\end{tabular}

Table 2: Pignistic probability and offers ranking

\begin{tabular}{|c|c|c|c|c|c|c|c|c|c|c|c|c|c|c|c|c|c|}
\hline \multicolumn{5}{|c|}{$\begin{array}{l}\text { Standard Method } \\
\text { ranking alternative } P\left(a_{i}\right)\end{array}$} & \multirow{2}{*}{$\frac{\text { ranking }}{10}$} & \multicolumn{2}{|c|}{ alternative $P\left(a_{i}\right)$} & \multicolumn{3}{|c|}{$\begin{array}{l}\text { Nascent Method } \\
\text { ranking alternative } P\left(a_{i}\right)\end{array}$} & \multirow{2}{*}{$\frac{\text { ranking }}{10}$} & \multicolumn{2}{|c|}{ alternative $P\left(a_{i}\right)^{T}$} & \multicolumn{3}{|c|}{$\begin{array}{l}\text { TIN-DS/AHP Method } \\
\text { ranking alternative } P\left(a_{i}\right)\end{array}$} & \multirow{2}{*}{$\frac{\text { ranking }}{10}$} \\
\hline$a_{1}$ & 0.0746 & 4 & $a_{6}$ & 0.2458 & & $a_{1}$ & 0.0971 & 5 & $a_{6}$ & 0.1952 & & $a_{1}$ & 0.0708 & 4 & $a_{6}$ & 0.2361 & \\
\hline$a_{2}$ & 0.0477 & 3 & $a_{7}$ & 0.1396 & 8 & $a_{2}$ & 0.0466 & 2 & $a_{7}$ & 0.136 & 9 & $a_{2}$ & 0.0485 & 3 & $a_{7}$ & 0.1365 & 8 \\
\hline$a_{3}$ & 0.0191 & 1 & $a_{8}$ & 0.1401 & 9 & $a_{3}$ & 0.0438 & 1 & $a_{8}$ & 0.1322 & 8 & $a_{3}$ & 0.0183 & 1 & $a_{8}$ & 0.1507 & 9 \\
\hline$a_{4}$ & 0.0935 & 6 & $a_{9}$ & 0.0216 & 2 & $a_{4}$ & 0.1042 & 6 & $a_{9}$ & 0.0509 & 3 & $a_{4}$ & 0.0963 & 6 & $a_{9}$ & 0.0205 & 2 \\
\hline$a_{5}$ & 0.1332 & 7 & $a_{10}$ & 0.0848 & 5 & $a_{5}$ & 0.1158 & 7 & $a_{10}$ & 0.0781 & 4 & $a_{5}$ & 0.1332 & 7 & $a_{10}$ & 0.0892 & 5 \\
\hline
\end{tabular}

$+1]$, treat them as $\overleftarrow{v}_{j}^{\left(n n^{\prime}\right)}$ and $\mathbf{v}_{j}^{\left(n n^{\prime}\right)}$. Specially, for enhancing the comparability of proposed method and nascent method, let $\bar{v}_{j}^{(n \Theta)}=v_{j}^{(n)}, n=1, \cdots, 4, j=1,2,3$. It's not hard to find, since the anolog data generated by proposed method exists twice fluctuations at gravity center and two vertexes, the accumulative fluctuating scale must be greater than anolog data in nascent method, the distortion is higher. The TIN knowledge matrix generated by above process is as shown in (17) ([ ] represents experts' group hasn't or needn't to judge relevant elements). Then according to step 5 to step 9 could realize the solving of BPA function (see details in Table 1 Line 4 ) and merits ranking of every alternative (Table 2 Column 13-18).

Need to be illustrated is, when using TIN-DS/AHP method to analog approach, because of total deviation of TIN knowledge matrix $\tilde{V}_{1}$ is $\tilde{\sigma}_{1}=0.2938$, which could not fulfill consistency threshold $\Delta_{1}=0.25$, so let revising efficiency parameter $\gamma_{1}=0.8$, revise knowledge matrix $\tilde{V}_{1}$ by using calculation model of this paper, acquiring the element greater than 0 in optimal solution of model is $\overleftarrow{r}_{1}^{\prime(12)}=0.267$, so revise element $\bar{v}_{1}^{(12)}$ corresponding to $\tilde{V}_{1}$ by referring (9) and (11), namely $\bar{v}_{1}^{\prime \prime(12)}=\bar{v}_{1}^{(12)}+\mathbf{r}_{1}^{(12)}$ $-\overleftarrow{r}_{1}^{(12)}=1.733$. Drag revised TIN knowledge matrix $\tilde{V}_{1}^{\prime \prime}$ into (7) again to get $\tilde{\sigma}_{1}=0.235<\Delta_{1}$, state that $\tilde{V}_{1}^{\prime \prime}$ is efficient, $\left(\tilde{m}_{j}^{(n)} \mid n=1, \cdots, 5\right)$ of optimal solution is the BPA function on this attribute.

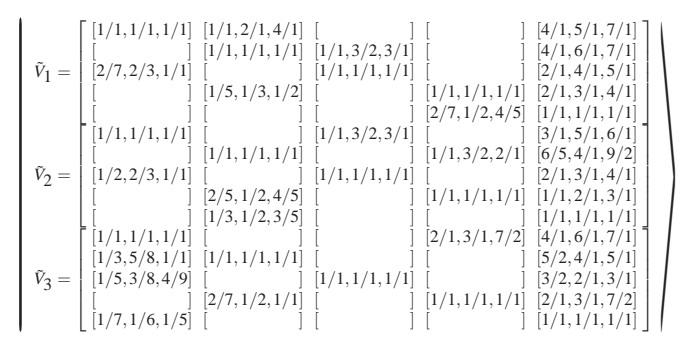

Standard BPA function and standard ranking could be as a consult basis to test scientificalness of nascent method and TIN-DS/AHP method since they have all the decision information relative to decision issue. Seen from obtained BPA function, the imitating deducing result and standard BPA function accumulative total deviation (sum of difference degree between BPA function on every alternative group and standard BPA function) of proposed method and nascent method are 0.199 and 1.817 , which state the BPA function got by TIN-DS/AHP method is closer to standard BPA function than nascent method. Seen from Pignistic probability and alternative ranking, the total deviations of Pignistic probability got from traditional method and standard BPA function are 0.037 and 0.174 . The alternative rankings got from proposed method and standard method are identical, moreover the ranking got from traditional method has numerous differences with standard method. Result above speaks volumes for the final evaluating result of this paper is more accurate than original method. The reasons why imitating evaluation result this paper is greater than traditional method obviously are: on one hand, the decision information sources of this paper are various. They could root in relative comparative judgment between alternative groups, or root in relative comparative judgment between alternative groups and Frame of Discernment (which the traditional method roots in). These sources are in favor of mutual corroboration and conflicts revising between decision information, which could guarantee the scientific validity of decision result. On the other hand, there is existing intelligent interaction revising mechanism in this paper (TIN knowledge matrix modified model and modified theorem), which could gradually get decision information fulfill to certain accuracy request. Compare with traditional method which just precede decision based on einmal deduce information simply, proposed is fitter for objective cognitive rules, could guarantee the applying feasibility of decision process. 


\section{Conclusions}

Current research findings of DS/AHP method actually belong to individual decision category, which are not fit for group decision-making issue that within reality that exist numbers of experts or the opinions of them full of divergences. In order to solve above problem, this paper firstly expounded relevant theory basis from DS/AHP method principle and TIN basic property. Secondly introduced deviation variable, and constructed determining model which could recognize optimal BPA function from TIN knowledge matrix, and aimed at possible inconformity problem which are possible existing inTIN knowledge matrix, put forward TIN knowledge matrix modified theorem which could define discussing issue, guide revising direction for experts' group. On this basis we have given intelligent decision process of TIN-DS/AHP method from human-machine intelligent interaction and intelligent decision view. Finally verified the methods of this paper are scientific validity and applying feasibility by using a numerical comparative analysis. The superiorities of the method of this paper are: firstly, we could deepen the cognitions of decision issue through interactive method, and by using TIN knowledge matrix to describe cognitive inference of experts' group, for one thing, it could overcome the defect which is lost easily in the process of decision information gathering, for another thing, it could also prevent the decision invalid problems which are caused by dispersive opinion of experts. Secondly, decision information not only could be derived from relatively judgment between group, but also could be derived from relatively judgement between group and recognition framework ( deficiency information is allowed, see equation (17)), which is benefit for experts with their own structure of knowledge to choose the most appropriate way to express deduction information, and also benefit for mutual corroboration and conflict revising between decision information. Thirdly, while the modified model of TIN knowledge matrix and modified theorem can affirm scientific nature of the whole information in original matrix , they also can define discussion issues, guide revising direction for experts' group, by which could realize intelligent interaction and intelligent decision between human being and computer, and improve decision efficiency and decision quality. Need to be illustrated is that the consistency threshold of TIN knowledge matrix mentioned in this paper, although could use the definition of Zhu Jianjun in 'Three-point Interval Number judgment matrix', the threshold they defined is closely related to the number of elements $N_{j}\left(N_{j}+1\right)$. So when imitate the definition of threshold proposed by them, we need to comprehensively consider the number of elements that are using for expressing deduction information of experts' group, by this way could guarantee the rationality of threshold designing.

\section{Acknowledgement}

This work is supported by National Natural Science Funds (71261011), China Postdoctoral Science Foundation Funded Project (20110491760), Application of Basic Research Project in Yunnan Province (2011FZ021), Key Project of Educational Commission in Yunnan Province (2012Z103), and Kunming University of Science and Technology Organizational Behavior and Complex Behavior Decision-making Innovation Team. The authors are grateful to the anonymous referee for a careful checking of the details and for helpful comments that improved this paper.

\section{References}

[1] M. J. Beynon. An expert system for multi-criteria decision making using Dempster Shafer theory. Expert Systems with Applications, 20, 357-67 (2001).

[2] M. J. Beynon. An investigation of the role of scale values in the DS/AHP method of multi-criteria decision making. Journal of Multi-Criteria Decision Analysis, 11, 327-43 (2002).

[3] M. J. Beynon, B. Curry, P.H. Morgan. The Dempster-Shafer theory of evidence: an alternative approach to multicriteria decision modelling. OMEGA, 28, 37-50 (2000).

[4] M. J. Beynon. DS/AHP method: A mathematical analysis, including an understanding of uncertainty. European Journal of Operational Research. 140, 104-17 (2002).

[5] M. J. Beynon. A method of aggregation in DS/AHP for group decision-making with the non-equivalent importance of individuals in the group. Computers \& Operations Research, 32, 1881-196 (2005).

[6] Y. Li, Y. Jiang, G. Zhao. Personnel Selection Based on DS/AHP. Psychological Exploration, 30, $72-7$ (2010).

[7] C. Li, C. Liu, T. Wu. Evaluating strategy opportunities using DS/AHP: Conference on Systems Science, Management Science and System Dynamics, (2007).

[8] G. Wei, J. Liu. A DS/AHP Method for Comprehensive Decision-making in Urban Power System Planning: China International Conference on Electricity Distribution, (2008).

[9] W. Duan, Y. Du, Y. Li. Operation Efficiency Evaluation Method for Spatial Structure of Human Capital Based on DS/AHP. Journal of Kunming University of Science and Technology (Social Science Edition), 12, 53-9 (2012).

[10] Z. Hua, B. Gong, X. Xu. A DS-AHP approach for multi-attribute decision making problem with incomplete information. Expert Systems with Applications, 34, 2221-7 (2008).

[11] Y. Yue, L. Liang. A DS/AHP Method for MultiAttributes Decision Making under Interval Uncertainty: 2nd International Conference on Modelling and Simulation, (2009).

[12] L. V. Utkin, V. S. Natalia. The DS/AHP Method Under Partial Information About Criteria And Alternatives By Several Levels Of Criteria. International Journal of Information Technology \& Decision Making, 11, 307-26 (2012). 
[13] J. Zhu, S. Liu, H. Wang. Aggregation Approach of Two Kinds of Three-Point Interval Number Comparison Matrix in Group Decision Making. Acta Automatica Sinica, 33 297-301 (2007).

[14] F. Tian, J. Zhu, D. Yao, H. Zhu. Consistency and weight estimation of novel three-point interval number complementary judgment matrix. Systems EngineeringTheory \& Practice, 28, 108-13 (2008).

[15] J. Zhu, C. Song, S. Liu. Consistency and weight estimation of three-point interval number comparison matrix. Journal of Systems Engineering, 23, 22-7 (2008).

[16] Y. Du, Y. Sun, W. Duan. Interactive method for deriving and fusing subjective evidences. Control and Decision, 26, 7326 (2011).

[17] Y. Du, K. Wang, W. Duan. Recognition Method for Key Knowledge Subjects in Knowledge Network International Review on Computers and Software, 7, 25-34 (2012).

[18] G. Moorhead, J. R. Montanari. Groupthink: A research methodology. Proceedings - 14th Annual Meeting of the American Institute for Decision Sciences, (1982).

[19] T. Kuno, H. Kuno, A. Irie. A deterministic approach to linear programs with Several Additional Mutiplicative Constraints. Computational Optimization and Applications, 14, 347-56 (1999).

[20] D. Li, Y. Du. Artificial Intelligence with Uncertainty. Beijing: National Defence Industry Press, (2005).

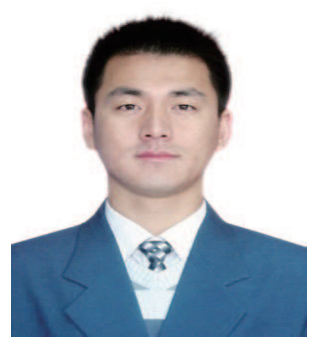

Yuanwei Du is Associate Professor with Faculty of Management and Economics at Kunming University of Science and Technology. $\mathrm{He}$ received the $\mathrm{PhD}$ degree in Management Science and Engineering at Jilin University. His research interests are in the areas of management decision innovation management information fusion and data mining. He has published research articles in reputed international journals of mathematical and engineering sciences.

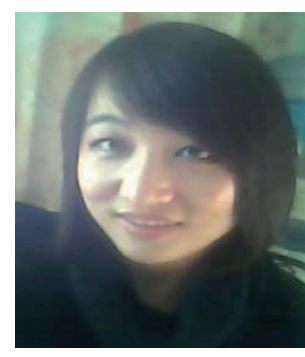

Chen Han is pursuing her Master Degree with Faculty of Management and Economics, Kunming University of Science and Technology, China. Her research interests are in the areas of management decision and logistics optimization.

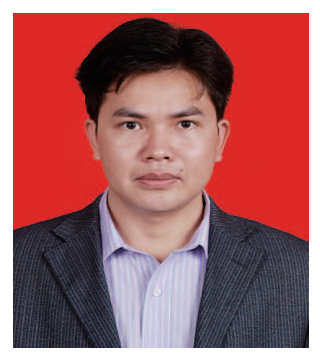

Youguo Jing is a lecturer with Faculty of Management and Economics, Kunming University of Science and Technology, China. His research interests are in the areas of logistics supply chain management and customize marketing.

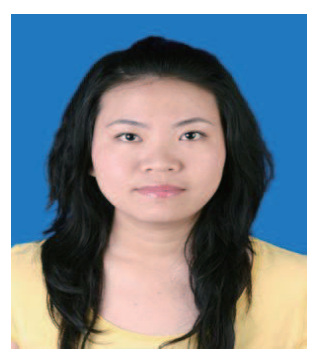

Jing Liu is pursuing her Master Degree with Faculty of Management and Economics, Kunming University of Science and Technology, China. Her research interests are in the areas of management decision information fusion. 